\title{
Introducción del dossier "Historizar las migraciones. Experiencias y discursos de movilidad y diversidad en perspectiva histórica"
}

\author{
Coordinadora: Verónica Hendel \\ vero_hendel@yahoo.com \\ Universidad Nacional de Luján - Universidad de \\ Buenos Aires - CONICET, Argentina
}

Cita sugerida: Hendel, V. (2021). Introducción del dossier

"Historizar las migraciones. Experiencias y discursos de movilidad y diversidad en perspectiva histórica" Anuario del Instituto de Historia Argentina, 21(2), e143.

https://doi.org/10.24215/2314257Xe143

\begin{abstract}
A lo largo de las últimas décadas, la historización de experiencias atravesadas por la migración y la movilidad ha comenzado a ocupar un lugar de mayor relevancia en el campo de la Ciencias Sociales y las Humanidades de la mano de los estudios poscoloniales, los estudios culturales y la historia desde abajo, entre otras corrientes y escuelas.

En la Argentina, los estudios que historizan el fenómeno migratorio lo han hecho desde distintos focos. Sin pretensión de exhaustividad, podemos encontrar aquellos trabajos que privilegian la reconstrucción de los debates históricos y fundacionales del Estado Nación (Halperin Donghi, 1998; Margulis et al, 1998). Las transformaciones en el plano legal, las políticas migratorias y los modelos de integración también han sido motivo de variadas producciones (Benencia, 2004; Novick, 2008; Pacecca, 2001). Algunos escritos han realizado un abordaje más global (Devoto, 2003; Mármora, 2004), mientras que otros han puesto la mirada en la dimensión territorial de las experiencias de migración (Sassone, 2021). También están los que se han enfocado en colectivos específicos y en historias locales (Artola, 2016; Cassanello, 2016; entre muchos otros).

Este dossier aborda el desafío de incorporar a los estudios sobre migración y movilidad una perspectiva histórica que enriquezca y complejice nuestra mirada sobre lo reciente. Partimos de la premisa de que el análisis del pasado es condición de necesidad para la comprensión de las experiencias actuales, teniendo
\end{abstract}


presente que ciertas imágenes y discursos del pasado suelen ser utilizadas, actualización mediante, para legitimar ciertos aspectos de los órdenes sociales actuales.

Las experiencias multifacéticas de migración y movilidad que emergen en lugares y periodos específicos requieren de conceptos que puedan dar cuenta de un modo más sutil y dinámico de su propia historia en el marco de procesos sociales y culturales más amplios. La tarea de recuperar la historia en estas experiencias no puede consistir simplemente en sumar un capítulo o un apartado de historia (Rockwell, 2018). En cambio, se trata de desarrollar una perspectiva que intente comprender "dialécticas complejas" que tienen lugar entre dinámicas centrales, tales como las formas hegemónicas de escolarización (en el caso de la educación) y tradiciones y culturas diversas que las atraviesan y confrontan en múltiples escalas espacio-temporales.

Historizar las experiencias de migración y movilidad supone, a su vez, desafíos metodológicos y teóricos vinculados a la forma de conceptualizar dichas dinámicas que suelen implicar múltiples temporalidades y espacialidades, a la frecuente carencia de fuentes primarias y a la necesidad de visibilizar procesos escondidos, invisibilizados u opacados por la historia liberal.

En este sentido, el objetivo de este dossier es difundir artículos que ayuden a promover un debate interdisciplinario entre la Historia y las Ciencias Sociales, y que contribuyan a entender cómo, a través de diferentes espacialidades, temporalidades e interseccionalidades de raza, género, clase y generación, las experiencias de migración y movilidad están imbricadas con procesos históricos que las constituyen y, en ciertos casos, condicionan.

El dossier que aquí presentamos incluye artículos elaborados por investigadoras de distintas disciplinas (Historia, Sociología, Antropología y Ciencias de la Comunicación) que recogen hallazgos y reflexiones derivados de los estudios que sobre el tema vienen realizando. En ellos se teje una cartografía que parte de diversas localidades de la Argentina (La Plata, Ciudad Autónoma de Buenos Aires, Córdoba y Chubut) y se abre hacia distintos lugares de América Latina y Europa, así como hacia múltiples temporalidades.

En el artículo que abre el dossier, "Aportar, agradecer y adaptarse. Discursos históricos y representaciones sociales docentes sobre la diversidad migratoria”, Paula Buratovich (Universidad de Buenos Aires) reconstruye los discursos de algunos de los representantes de la élite política de fines de siglo XIX y principios de siglo XX rastreando los devenires de la noción de instrumentalidad de la migración. Para ello crea un corpus integrado por obras de José María Ramos Mejía, José Ingenieros y Ricardo Rojas. Luego, establece los puentes que identifica entre el modo en que allí se caracteriza la figura del migrante externo y las representaciones sociales que construyen docentes y directivos del Área Metropolitana de Buenos Aires en la actualidad.

En su artículo, "Trayectorias migrantes, movilidad social y recambio étnico nacional en la horticultura (La Plata, Argentina, siglo XX-XXI)", Soledad Lemmi (Universidad Nacional de La Plata - CONICET) y María Alejandra Waisman (Universidad Nacional de La Plata) reconstruyen las trayectorias socioproductivas de horticultores/as del periurbano hortícola de la ciudad de La Plata. Este ejercicio les permite explicar los recambios en la estructura social hortícola acontecidos en las últimas décadas. En su análisis, hacen converger los procesos históricos más amplios y las repercusiones en el espacio local, los condicionamientos estructurales y el punto de vista de los/as agentes protagonistas que viven y producen en el periurbano platense. En este recorrido, dan cuenta de que las trayectorias están atravesadas por adscripciones étniconacionales diferenciales: migración de origen europeo y boliviana, diferentes profundidades temporales y tendencias contrastantes. La movilidad social ascendente y el recambio étnico/nacional emergen como dos aspectos centrales en las transformaciones históricas del tejido social hortícola platense. Abordando el mismo contexto geográfico, Melina Morzilli (Universidad Nacional de La Plata- CONICET) presenta una revisión de los estudios que han analizado la inclusión socioeducativa de la población migrante boliviana en el ciclo superior, historizando este campo de reciente desarrollo. En su artículo, "Educación superior y migración boliviana. Trayectorias educativas de jóvenes provenientes de familias migrantes bolivianas", ofrece un recorrido por los estudios que, a través de datos estadísticos y testimonios, dan cuenta de 
que migrantes bolivianos/as se encuentran asistiendo al nivel educativo superior en diferentes territorios: Córdoba, Mendoza, Río Negro, Santa Fe, Capital Federal y provincia de Buenos Aires.

El artículo de Melisa Brenda Di Paolo (Universidad de Buenos Aires), "Modalidades escolares y tendencias poblacionales en la Meseta Central de Chubut, Argentina” propone un recorrido por las formas que ha adoptado el proceso de escolarización en esta zona en vinculación dialógica con sus cambios económicos y migratorios. En el marco del mismo, se diferencian tres períodos del desarrollo territorial que dan cuenta de los modos en que las dinámicas poblacionales de repoblamiento, despoblamiento y concentración estimularon y guiaron el sistema escolar en la Meseta. Transformaciones que fueron, a su vez, impulsadas y profundizadas por las modalidades que fue asumiendo la escuela en este territorio. En este caso, la historización de los procesos de escolarización se torna condición de inteligibilidad del presente.

Un abordaje diferente nos propone Nadia Chiaravalloti (Universidad Nacional de Luján-Universidad de Buenos Aires) en su análisis de "Los viajes como rupturas transformadoras de las memorias sociales territorializadas". El artículo se propone historizar la Educación Intercultural Bilingüe (EIB) en Argentina, a partir de la biografía de vida de Marta Tomé. Educadora, pionera y referente de la temática. Pero elige para ello un recorrido muy particular: los viajes que la docente realizó a lo largo de su juventud, por varios países de Latinoamérica, dado que entiende que representan rupturas transformativas que influyeron en su militancia y compromiso por la educación. A partir de dicha reconstrucción describe una serie de prácticas interculturales que se generaron en diversos territorios, y que hoy hacen a la memoria social y territorializada de la educación intercultural en Argentina.

El artículo que cierra el dossier también se ubica en el campo de los estudios sobre movilidad pero con foco en la provincia de Córdoba. En el artículo “Idas y venidas' entre Bolivia y Argentina. Retornos cíclicos en las movilidades bolivianas contemporáneas", Florencia Maggi (Universidad Nacional de CórdobaCONICET) problematiza el traslado de modelos de periodización construidos a escala nacional sobre las movilidades bolivianas en la Argentina para el análisis de procesos situados en otros territorios y propone una relectura atenta a las especificidades locales contemporáneas que complejizan la formulación de los períodos más recientes al relativizar el supuesto de fijación residencial. A partir del trabajo etnográfico, reconstruye procesos de circulación migratoria con retornos cíclicos y diversas formas de multiterritorialización que habilitan a pensar en estrategias transnacionales de apropiación de los territorios por parte de les migrantes.

Los aportes que estos artículos ofrecen, así como las propuestas metodológicas y teóricas que las autoras despliegan a propósito de los temas, problemas y contextos que abordan, ponen en evidencia algunas apuestas significativas de historización de las experiencias de migración y movilidad. También brindan un conjunto de estrategias y perspectivas propias basadas en los desafíos que cada experiencia les propone. Este conjunto de indagaciones hace visible la potencia del abordaje de experiencias y discursos de movilidad y diversidad en perspectiva histórica, abriendo camino a nuevas y más profundas reflexiones e indagaciones.

\section{ReFERENCiAS}

Artola, J. (ed.) (2016). Los inmigrantes en la construcción de la Argentina. Buenos Aires: OIM.

Benencia, R. (2004). "La existencia de modelos históricos contrapuestos en la integración de los migrantes en la sociedad argentina”. Amérique Latine Histoire et Mémoire. Les Cabiers ALHIM, 9.

Cassanello, C. (2016). Migración, identidad y memoria. Los bolivianos en la Argentina (1970-2010). Buenos Aires: UNQ.

Devoto, F. (2003). Historia de la inmigración en la Argentina. Buenos Aires: Sudamericana.

Halperín Donghi, T. (1998). El espejo de la historia. Problemas argentinos y perspectivas latinoamericanas. Buenos Aires: Sudamericana.

Margulis, M. et al. (1998). La segregación negada: cultura y discriminación social. Buenos Aires: Biblos.

Mármora, L. (2004). Las políticas de migraciones internacionales. Buenos Aires: Editorial Paidós. 
Novick, S. (2008). "Migración y Políticas en Argentina: Tres leyes para un país extenso (1876-2004)". En S. Novick, (comp.), Las migraciones en América Latina. Buenos Aires: Catálogos.

Pacecca, M. I. (2001). Migrantes de ultramar, migrantes limitrofes. Politicas migratorias y procesos clasificatorios. Argentina, 1945-1970. Buenos Aires: CLACSO.

Rockwell, E. (2018). Vivir entre escuelas: relatos y presencias. Buenos Aires: CLACSO.

Sassone, S. M. (et al) (2021). Migraciones internacionales en la Argentina: panorama socioterritorial en tiempos del Bicentenario. CABA: Instituto Multidisciplinario de Historia y Ciencias Humanas. 